\title{
Supporting Information: An Atomic Hourglass and Thermometer Based on Diffusion of a Mobile Dopant in $\mathrm{VO}_{2}$
}

Diane G. Sellers, ${ }^{\dagger}, \#$ Erick J. Braham, ${ }^{\dagger, \#}$ Ruben Villarreal, ${ }^{\S}$ Baiyu Zhang,,${ }^{\ddagger}$ Abhishek Parija,,${ }^{\dagger}$ Timothy D.

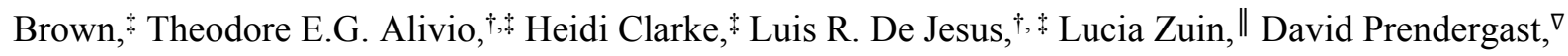
Xiaofeng Qian, ${ }^{\ddagger *}$ Raymundo Arroyave, $\$, \$, *$ Patrick J. Shamberger, ${ }^{\ddagger *}$ Sarbajit Banerjee ${ }^{\dagger, * *}$

${ }^{\dagger}$ Department of Chemistry, Texas A\&M University, College Station, TX 77843, USA

${ }^{\ddagger}$ Department of Materials Science and Engineering, Texas A\&M University, College Station, TX 77843, USA

$\S$ Department of Mechanical Engineering, Texas A\&M University, College Station, TX 77843, USA

${ }^{\wedge}$ Department of Industrial and Systems Engineering, Texas A\&M University, College Station, TX 77843, USA

\|Canadian Light Source, University of Saskatchewan, Saskatoon, Canada

${ }^{\nabla}$ The Molecular Foundry, Lawrence Berkeley National Laboratory, Berkeley, California 94720, USA

E-mail:feng@tamu.edu; raymundo.arroyave@tamu.edu; patrick.shamberger@tamu.edu; banerjee@,chem.tamu.edu

\section{Supporting Methods}

In order to determine the Fermi level, native defect calculations have been performed, as shown in Fig. S6C and S6D. The equilibrium Fermi level is computed by solving self-consistent equations under the charge neutrality conditions given by $(58)$

$$
-n_{e}\left(E_{F}, T\right)+n_{h}\left(E_{F}, T\right)+\sum_{D} \sum_{q} q_{D} \cdot c_{D, q}\left(E_{F}, T\right)=0,
$$

where $c_{D, q}\left(E_{F}, T\right), n_{e}$ and $n_{h}$ are defect, free electron and hole concentrations, respectively. They can be calculated as the following:

$$
\begin{gathered}
c_{D, q}\left(E_{F}, T\right)=N_{S i t e} \mathrm{e}^{-\frac{E_{P}^{D, q}\left(_{F}\right)}{k_{B} T}} \ldots(\mathrm{S} 1) \\
n_{e}\left(E_{F}, T\right)=\int_{C B M}^{+\infty} g_{e}(E) f\left(E-E_{F}, T\right) d E \ldots(\mathrm{S} 2) \\
n_{h}\left(E_{F}, T\right)=\int_{-\infty}^{V B M} g_{h}(E)\left(1-f\left(E-E_{F}, T\right)\right) d E \ldots(
\end{gathered}
$$

$f\left(E-E_{F}, T\right)$ is the Fermi-Dirac distribution. $g_{e}(E)$ and $g_{h}(E)$ are the density of states (DOS) of electrons and holes, respectively. Based on the calculated formation energies, the equilibrium Fermi levels are $0.5 \mathrm{eV}$ and $0.55 \mathrm{eV}$ for O-rich and O-poor conditions, respectively. The corresponding electron densities are $\sim 10^{19} \mathrm{~cm}^{-3}$ and $\sim 10^{20} \mathrm{~cm}^{-3}$, and the hole densities are $10^{14}$ $\mathrm{cm}^{-3}$ and $10^{13} \mathrm{~cm}^{-3}$, respectively.

\section{$\underline{\text { Supporting Experimental Results }}$}



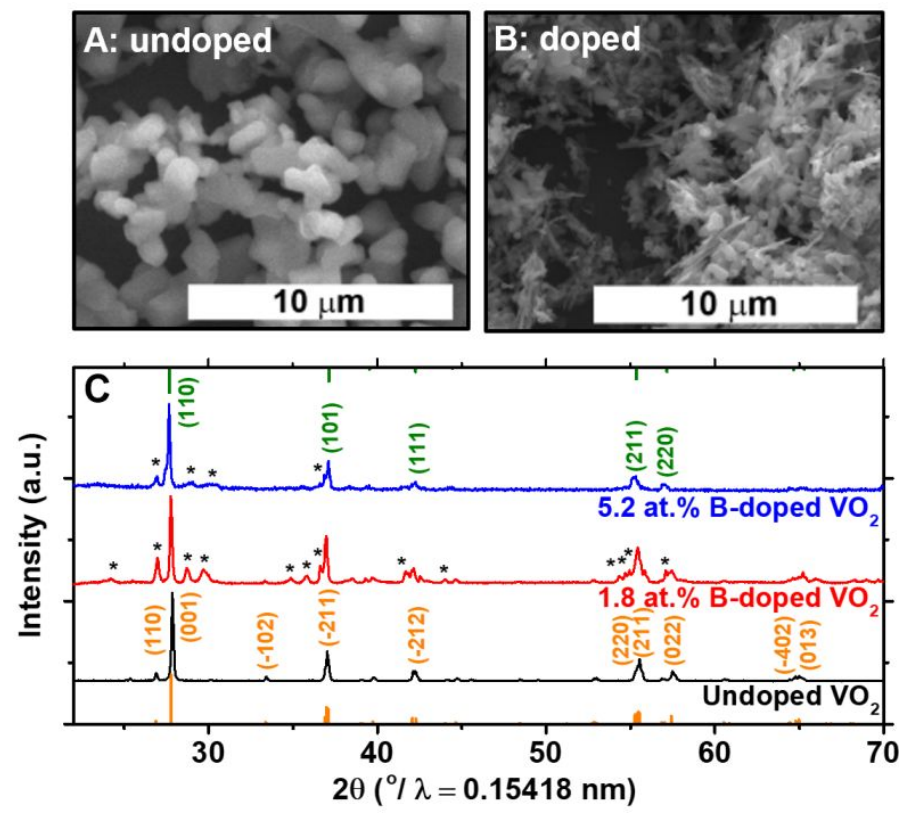

Fig. S1: Structural Characterization of B-Doped $\mathbf{V O}_{2}$. SEM images show A) undoped and B) $\mathrm{B}_{0.018} \mathrm{VO}_{2}$; the annealing step resulted in the incorporation of $\mathrm{B}$ atoms within interstitial sites of $\mathrm{VO}_{2}$ and induces the sintering of $\mathrm{VO}_{2}$ nanowires into irregular shaped platelets with lateral dimensions extending to $1.9 \pm 1.0 \mu \mathrm{m}$. C) Powder XRD pattern in the $2 \theta$ range from $22-70^{\circ}$ of undoped $\mathrm{VO}_{2}, \mathrm{~B}_{0.018} \mathrm{VO}_{2}$, and $\mathrm{B}_{0.052} \mathrm{VO}_{2}$ acquired at $22^{\circ} \mathrm{C}$. Reflections corresponding to the $\mathrm{M}_{1}$ phase of $\mathrm{VO}_{2}$ are plotted along the bottom axis as per Joint Committee on Powder Diffraction Standards (JCPDS) \# 043-1051, whereas reflections corresponding to the $\mathrm{R}$ phase of $\mathrm{VO}_{2}$ are plotted along the top axis as per JCPDS \# 79-1655. Undoped and $\mathrm{B}_{0.02} \mathrm{VO}_{2}$ samples are indexed to the $\mathrm{M}_{1}$ phase of $\mathrm{VO}_{2}$, whereas the pattern for the $\mathrm{B}_{0.05} \mathrm{VO}_{2}$ sample is indexed to the $\mathrm{R}$ polymorph of $\mathrm{VO}_{2}$. The incorporation of $\mathrm{B}$ atoms depresses the $\mathrm{M}_{1} \rightarrow \mathrm{R}$ transition temperature by ca. $10^{\circ} \mathrm{C} /$ at. $\% \mathrm{~B}(22)$ such that the observed stabilization of $\mathrm{R}$ polymorph at room temperature for the $\mathrm{B}_{0.05} \mathrm{VO}_{2}$ sample is consistent with a depression of the critical transition temperature for 5.2 at.\% B-doping. Reflections derived from a minority $\mathrm{V}_{8} \mathrm{O}_{15}$ phase (JCPDS no. 71-0041) are asterisked and are thought to arise from increased $\mathrm{VO}_{2}$ reduction(22) but do not contribute to the observed MIT behavior.(30) No evidence is observed for crystalline boron oxides or orthorhombic/ $\mathrm{M}_{2}$ phases of $\mathrm{VO}_{2}$, which have been reported previously to be associated with interstitial hydrogen incorporation,(27) substitutional doping of trivalent cations,(28) and anisotropic strain.(29) 

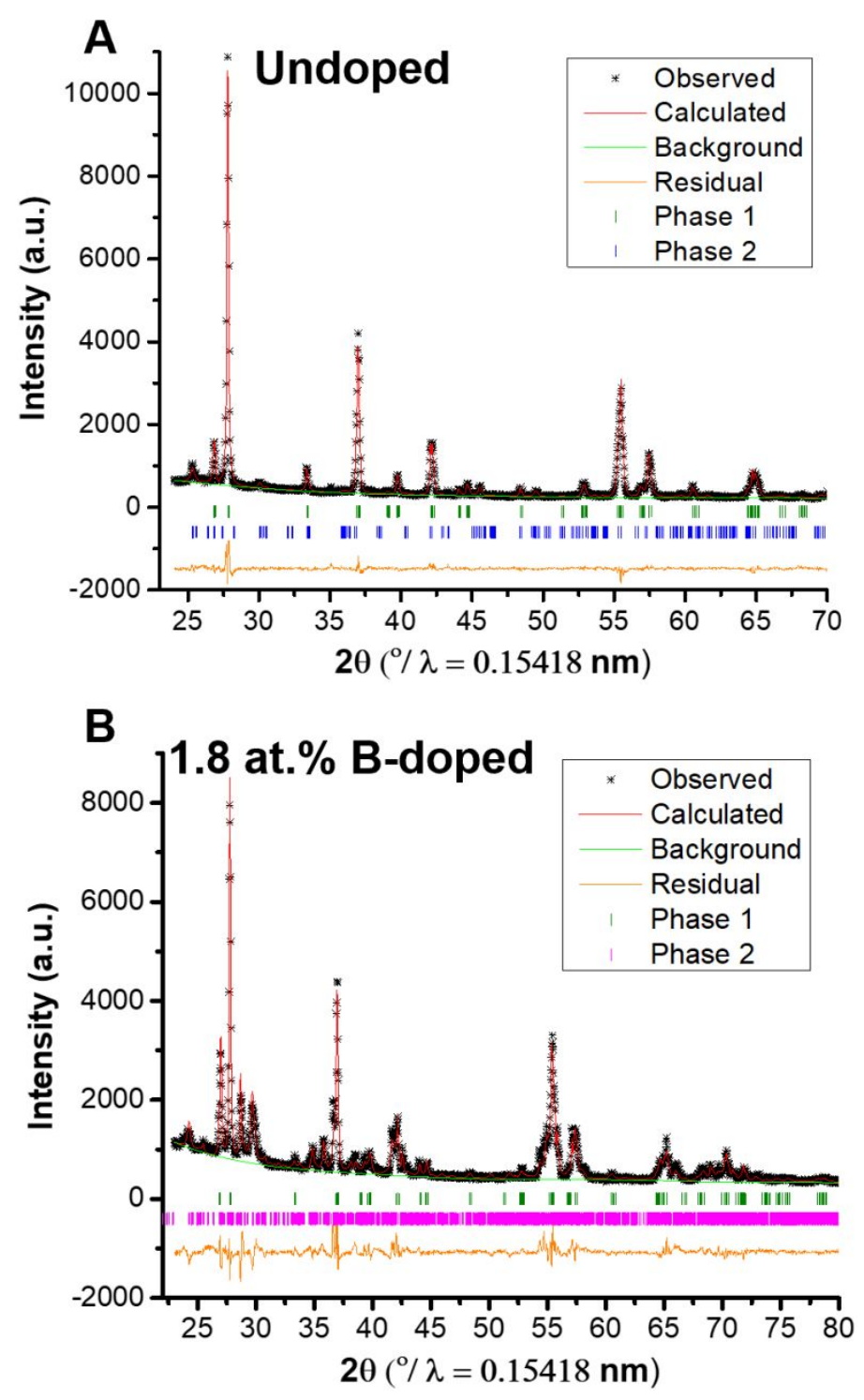

Fig. S2: Rietveld refinement of powder $\mathrm{X}$-ray diffraction pattern of undoped $\mathrm{VO}_{2}$ and $\mathbf{B}_{\mathbf{0 . 0 1 8}} \mathrm{VO}_{2}$. A) Undoped $\mathrm{VO}_{2}$ was subjected to rapid thermal annealing without inclusion of 2allyl-4,4,5,5-tetramethyl-1,3,2-dioxaborolane; two distinctive phases are identified, monoclinic $\mathrm{M}_{1} \mathrm{VO}_{2}$ and phase 2 and trificlinic $\mathrm{V}_{6} \mathrm{O}_{13}$. See also Table $\mathrm{S} 1$. B) Phase 1 is monoclinic $\mathrm{M}_{1} \mathrm{VO}_{2}$ and phase 2 is the triclinic $\mathrm{V}_{8} \mathrm{O}_{15}$ impurity phase. Two distinctive phases are identified, monoclinic $\mathrm{M}_{1} \mathrm{VO}_{2}$ and phase 2 and triclinic $\mathrm{V}_{8} \mathrm{O}_{15}$. See also Table $\mathrm{S} 1$.

Table S1. Rietveld refinement parameters Tabulated parameters from a Rietveld refinement of powder XRD patternes for undoped $\mathrm{VO}_{2}$ subjected to rapid thermal annealing without addition of the 2-allyl-4,4,5,5-tetramethyl-1,3,2-dioxaborolane precursor and 1.8 at.\% B-doped $\mathrm{VO}_{2}$. Refinement statistics, including goodness of fit $\left(\chi^{2}\right)$, weighted goodness of fit (wRp) and the individual point residuals ( $\mathrm{Rp})$ are listed. 


\begin{tabular}{|c|c|c|}
\hline \multicolumn{3}{|l|}{ Undoped $\mathrm{VO}_{2}$} \\
\hline \multicolumn{3}{|c|}{ Phase 1: $\mathrm{VO}_{2}\left(\mathrm{M}_{1}\right) / /$ Space Group: P1 21/c $1 / /$ Wt. Fraction: 0.8662(5)// Vol: $118.290(4) \AA^{3}$} \\
\hline$\alpha=90.000(0)^{\circ}$ & $\beta=122.597(3)^{\circ}$ & $\gamma=90.000(0)^{\circ}$ \\
\hline$a=5.7561(1)$ & $b=4.529(2)$ & $c=5.385(2)$ \\
\hline $\mathrm{X}^{2}=2.282$ & $w R p=0.0692$ & $\mathrm{Rp}=0.0538$ \\
\hline \multicolumn{3}{|c|}{ Phase 2: $\mathrm{V}_{6} \mathrm{O}_{13} / /$ Space Group: $C 1$ 2/m 1// Wt. Fraction: 0.133(3) // Vol: 437.9(2) $\AA^{3}$} \\
\hline$\alpha=90.000(0)^{\circ}$ & $\beta=101.15(4)^{\circ}$ & $\gamma=90.000(0)^{\circ}$ \\
\hline$a=11.943(3)$ & $b=3.6818(7)$ & $c=10.149(4)$ \\
\hline $\mathrm{X}^{2}=2.282$ & $\mathrm{wRp}=0.0692$ & $\mathrm{Rp}=0.0538$ \\
\hline \multicolumn{3}{|c|}{1.8 at.\% B-doped $\mathrm{VO}_{2}$} \\
\hline \multicolumn{3}{|c|}{ Phase 1: $\mathrm{VO}_{2}\left(\mathrm{M}_{1}\right) / /$ Space Group: P1 21/c $1 / /$ Wt. Fraction: 0.389(2) // Vol: $118.77(2) \AA^{3}$} \\
\hline$\alpha=90.000(0)^{\circ}$ & $\beta=122.512(8)^{\circ}$ & $\gamma=90.000(0)^{\circ}$ \\
\hline$a=5.7635(5)$ & $b=4.5291(4)$ & $c=5.3953(8)$ \\
\hline $\mathrm{X}^{2}=5.824$ & $\mathrm{wRp}=0.0907$ & $\mathrm{Rp}=0.0699$ \\
\hline \multicolumn{3}{|c|}{ Phase 2: $\mathrm{V}_{8} \mathrm{O}_{15}$ (triclinic) // Space Group: $P-1 / / \mathrm{Wt}$. Fraction: 0.610(3) // Vol: $916.702(0) \AA^{3}$} \\
\hline$\alpha=99.060(8)^{\circ}$ & $\beta=128.398(8)^{\circ}$ & $\gamma=108.925(6)^{\circ}$ \\
\hline$a=5.431(7)$ & $b=7.0128(3)$ & $c=37.098(4)$ \\
\hline $\mathrm{X}^{2}=5.824$ & $\mathrm{wRp}=0.0907$ & $\mathrm{Rp}=0.0699$ \\
\hline
\end{tabular}



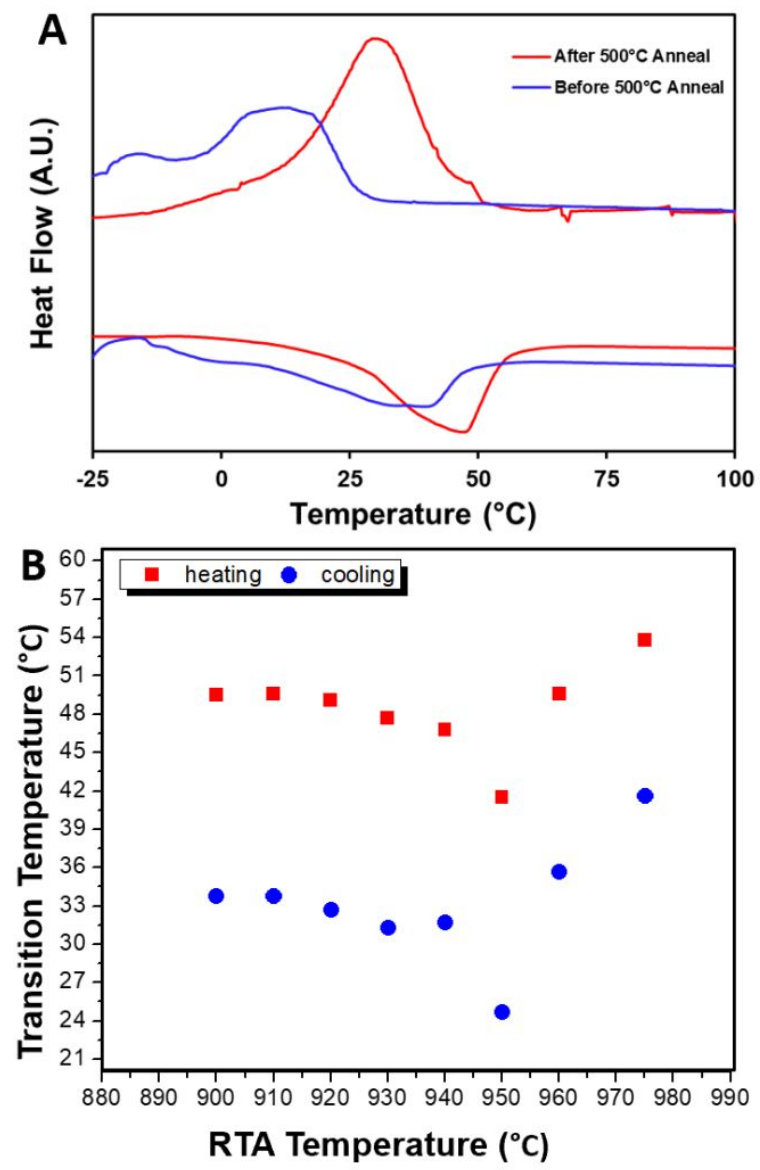

Fig. S3: Boron annealing results A) DSC trace for boron doped $\mathrm{VO}_{2}$ with cycles before (blue) and after (red) an annealing step within the DSC of a $500^{\circ} \mathrm{C}$ isothermal hold for 2 hours. The shift to higher transition temperature for the heating and cooling transition is indicative of the boron diffusing out of the lattice at high temperature effectively lowering the observed dopant concentration. B) Resulting peak transition temperatures for samples synthesized at various rapid thermal anneal (RTA) temperatures with the boron precursor. The depression leading up to $950^{\circ} \mathrm{C}$ indicates an optimal temperature for the degradation of the precursor and diffusion of boron in without overshooting to higher temperatures allowing diffusion of boron out of the lattice again. 

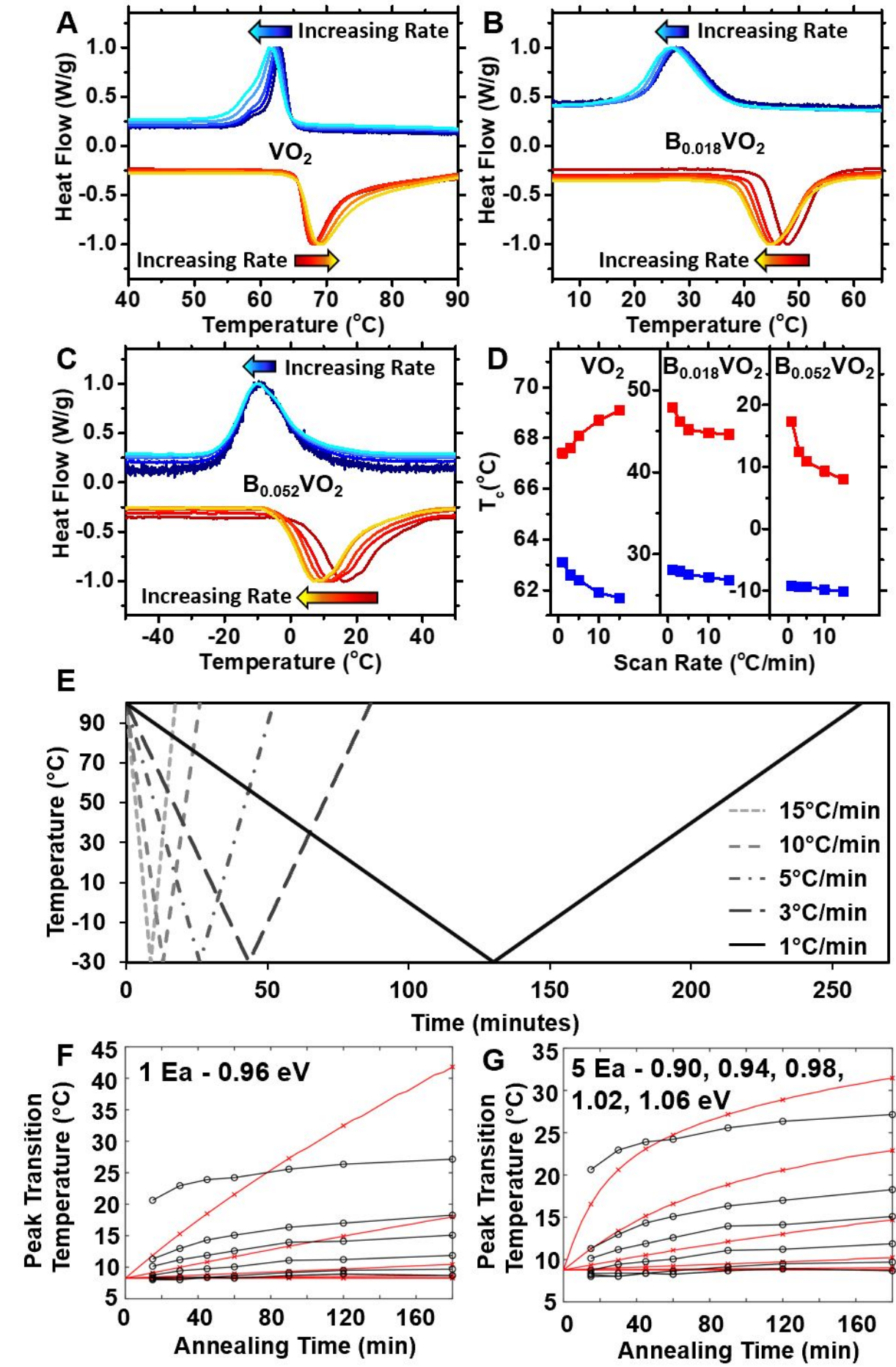

Fig. S4: Additional DSC results - Rate and annealing dependence. Rate-dependent DSC traces for A) $\mathrm{VO}_{2}$, B) $\mathrm{B}_{0.018} \mathrm{VO}_{2}$, and C) $\mathrm{B}_{0.052} \mathrm{VO}_{2}$. The red and blue traces depict the evolution of the heating and cooling transitions, respectively, as a function of the scan rate. The shading of the trace represents the scan rate such that the slowest rate $\left(1^{\circ} \mathrm{C} / \mathrm{min}\right)$ is the darkest and the fastest rate $\left(15^{\circ} \mathrm{C} / \mathrm{min}\right)$ is the lightest coloration. The resulting $T_{c}$ values from $(\mathrm{A})-(\mathrm{C})$ are plotted as a function of scan rate in D) with the heating transition in red and cooling transition in blue. E) Thermal profile applied during the rate-dependent DSC experiment for undoped $\mathrm{VO}_{2}$ 
and $\mathrm{B}_{0.02} \mathrm{VO}_{2}$ samples, the $\mathrm{B}_{0.05} \mathrm{VO}_{2}$ sample was cooled to $-60^{\circ} \mathrm{C}$ owing to the lower shifted MIT but followed the same rate pattern. The dash type and shade of the line delineates rate with the most broken/lightest line being the fastest and the unbroken/darkest line as the slowest. F) and G) show arrhenius models for 49 isothermal experiments described in Fig. 2 as a function of varying time and temperature at which the sample was held in the monoclinic $\mathrm{M}_{1}$ phase. Black circles represent the experimental data and red curves and crosses denote the model predictions. Each line represents a different isothermal temperature of $-50,-40,-30,-20,-10,0$, and $10^{\circ} \mathrm{C}$ ascending from the bottom of the plots. F represents a single activation energy of $0.96 \mathrm{eV}$, whereas $\mathrm{G}$ represents a combination of 5 activation energies of $0.90,0.94,0.98,1.02$, and 1.06 $\mathrm{eV}$ in equal contribution.

Rate Dependent DSC Experiment Schematic Sample: $\mathrm{B}_{0.018} \mathrm{VO}_{2}$

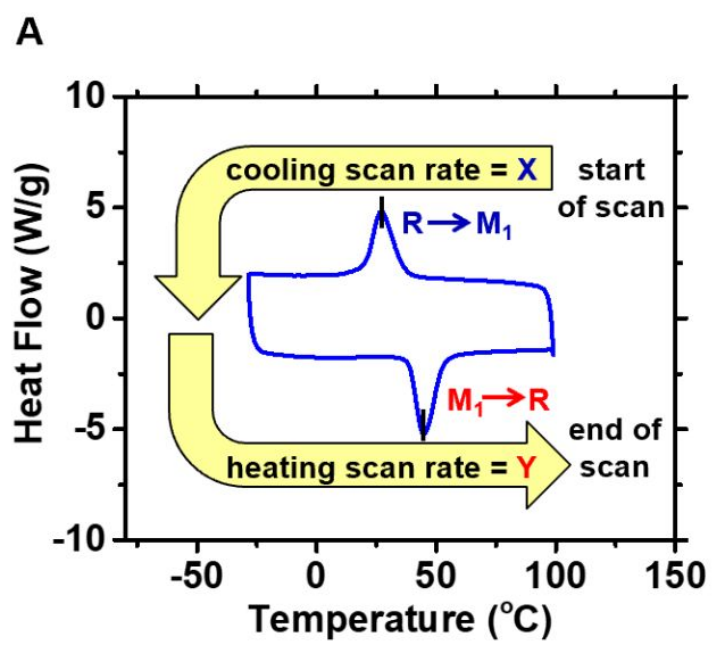

Experiment 2: $\left(X=1^{\circ} \mathrm{C} / \mathrm{min}, \mathrm{Y}=1-15^{\circ} \mathrm{C} / \mathrm{min}\right)$ Constant Cooling Rate, Variable Heating Rate

D In situ DSC Thermal Profile

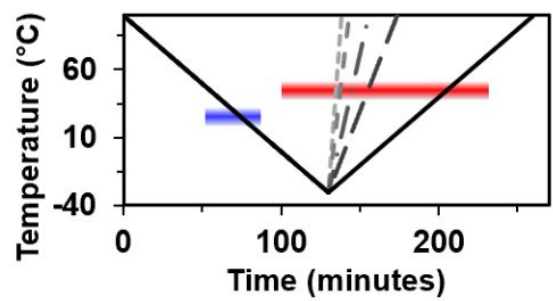

E Resulting Transition Temperatures

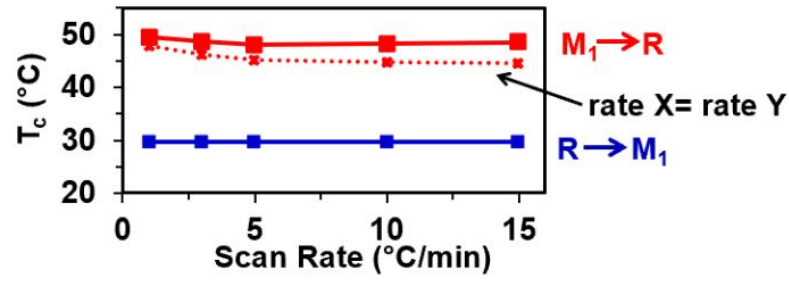
$-15^{\circ} \mathrm{C} / \mathrm{min}$
$--10^{\circ} \mathrm{C} / \mathrm{min}$
$--5^{\circ} \mathrm{C} / \mathrm{min}$
$--3^{\circ} \mathrm{C} / \mathrm{min}$
$-1^{\circ} \mathrm{C} / \mathrm{min}$
Experiment 1: $\left(X=1-15^{\circ} \mathrm{C} / \mathrm{min}, Y=1{ }^{\circ} \mathrm{C} / \mathrm{min}\right)$ Variable Cooling Rate, Constant Heating Rate

B In situ DSC Thermal Profile

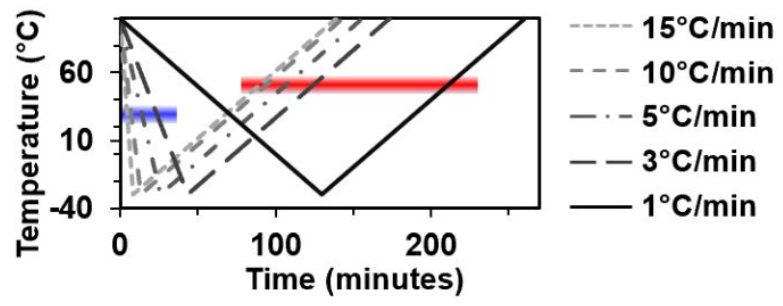

C Resulting Transition Temperatures

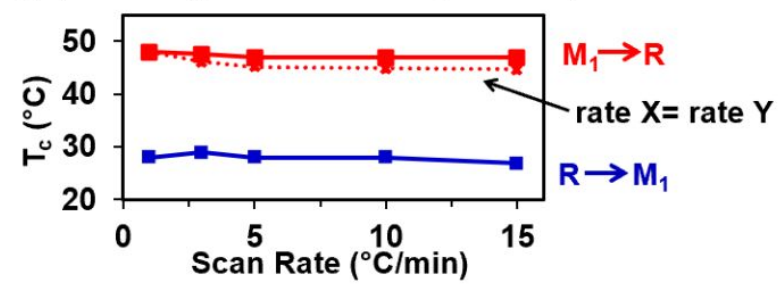

Experiment 3: $\left(X=1^{\circ} \mathrm{C} / \mathrm{min}, Y=1-15^{\circ} \mathrm{C} / \mathrm{min}\right)$ Constant Cooling Rate, Variable Heating Rate Comparing Two Turnaround Temperatures

F In situ DSC Thermal Profile

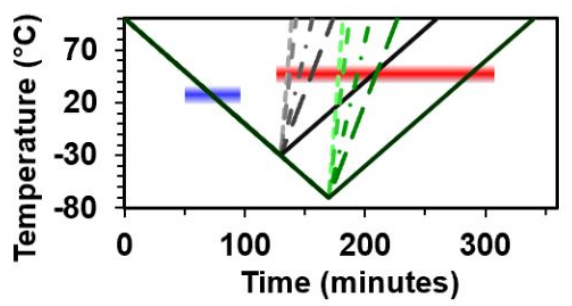

---- $15^{\circ} \mathrm{C} / \mathrm{min}$

G Resulting Transition Temperatures

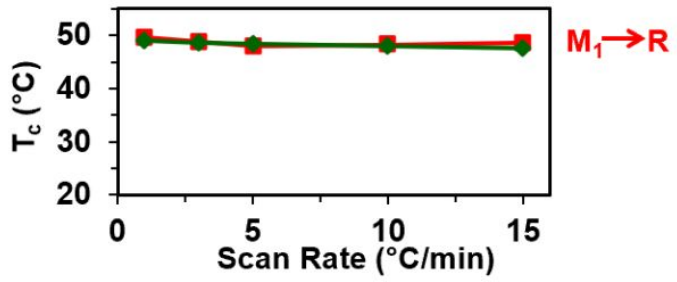


Fig. S5: Additional DSC results - Rate and turnaround dependence. A) Illustration of the procedure employed in DSC Experiments 1-3 for evaluation of a $\mathrm{VO}_{2}$ sample with 1.8 at.\% $\mathrm{B}$ in interstitial sites. Experiment 1 involves varying the cooling rate whilst holding the heating rate at $1^{\circ} \mathrm{C} / \mathrm{min}(\mathrm{B}, \mathrm{C})$; experiment 2 involves varying the heating rate whilst holding the cooling rate at $1^{\circ} \mathrm{C} / \mathrm{min}(\mathrm{D}, \mathrm{E})$; and experiment 3 involves varying the heating rate whilst holding the cooling rate at $1{ }^{\circ} \mathrm{C} / \mathrm{min}$ and comparing turn around temperatures of $-30^{\circ} \mathrm{C}$ and $-70^{\circ} \mathrm{C}(\mathrm{F}, \mathrm{G})$. For each experiment, the thermal profiles $(\mathrm{B}, \mathrm{D}, \mathrm{F})$ and resulting $T_{c}$ values plotted as a function of scan rate $(\mathrm{C}, \mathrm{E}, \mathrm{G})$ are given. The $T_{c}$ values of the heating transition for the full scan rate dependent measurement shown in Fig. S3D have been added to $\mathrm{C}$ and $\mathrm{E}$ as a dotted line for comparison. These measurements are aimed at separately evaluating the rate dependence of the $\mathrm{R} \rightarrow \mathrm{M}_{1}$ and $\mathrm{M}_{1} \rightarrow \mathrm{R}$ transitions and evaluating the influence of time spent within the low-temperature phase. The resulting $T_{\mathrm{c}}$ values for constant heating rate and constant cooling rate measurements are shown in $\mathrm{C}$ and $\mathrm{E}$, respectively, and both exhibit $T_{\mathrm{c}}$ of the heating transition $\left(\mathrm{M}_{1} \rightarrow \mathrm{R}\right)$ to decreases only marginally with increasing scan rate in comparison to the fully rate dependent scans with shifts of less than $1.0^{\circ} \mathrm{C}$ for both constant heating and constant cooling measurements. Such a result indicates that kinetic asymmetry does not originate in rate-dependent behavior of either of the transitions and suggests that the observed phenomenon derives from the residence time within the $\mathrm{M}_{1}$ phase. For the experiment in $\mathrm{F}$ and $\mathrm{G}$ the cooling rate was held constant while the heating rate was varied as in $\mathrm{D}$, but for two different turnaround temperatures, $-30^{\circ} \mathrm{C}$ and $70^{\circ} \mathrm{C}$. The difference in $T_{c}$ between the $-30^{\circ} \mathrm{C}$ and $-70^{\circ} \mathrm{C}$ measurements was negligible indicating that the time the sample spent lower than $-30^{\circ} \mathrm{C}$ does not impact the $\mathrm{M}_{1} \rightarrow \mathrm{R}$ transition temperature for this sample. 

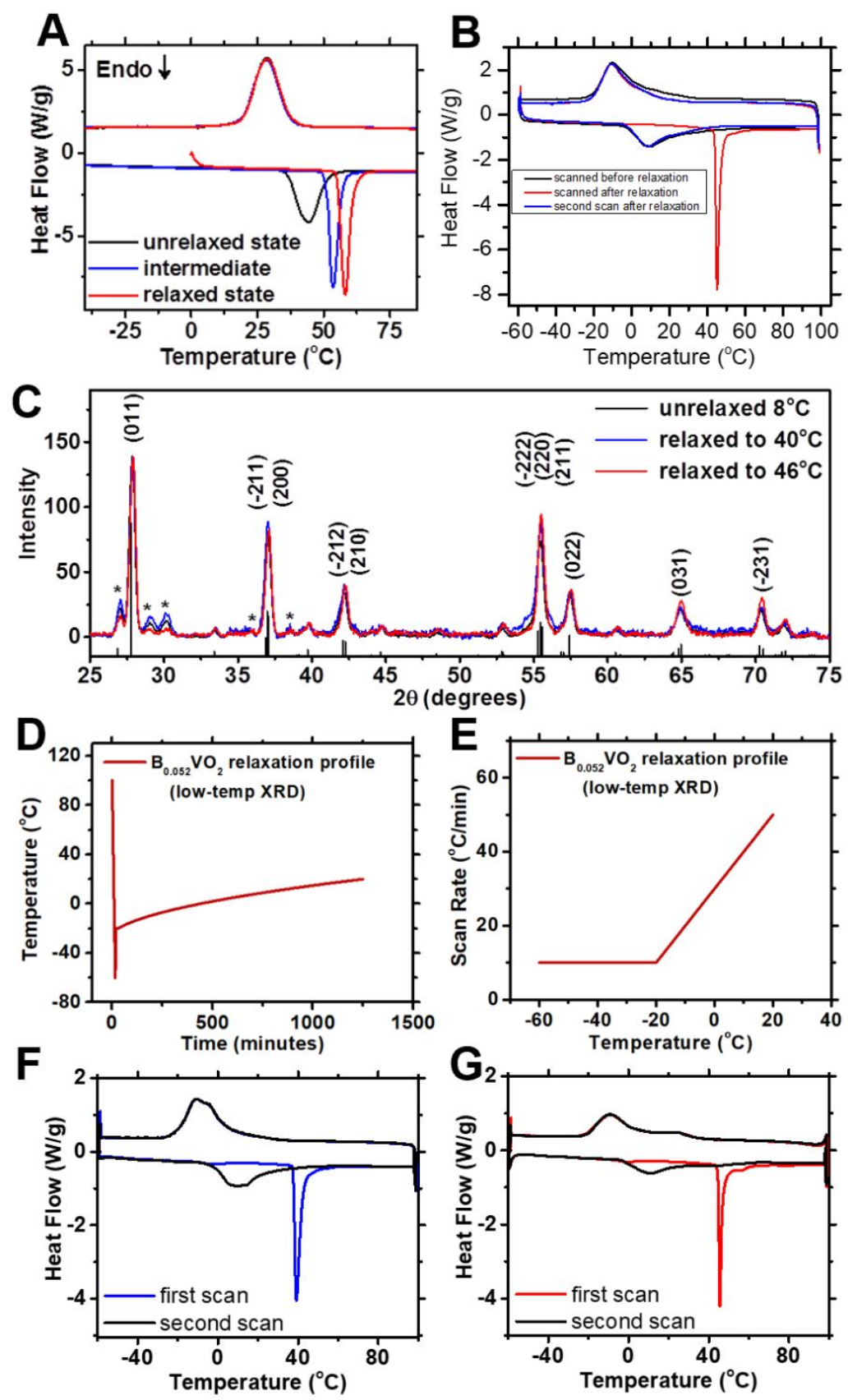

Fig. S6: Probing Quenched and Relaxed States of B-Doped $\mathbf{V O}_{2}$. A) DSC traces of $\mathrm{B}_{0.018} \mathrm{VO}_{2}$ in the unrelaxed (quenched) state, and states that were thermally-relaxed as a function of time at room temperature amounting to intermediate (40 days) and relaxed (323 days) structures. B) DSC traces of $\mathrm{B}_{0.052} \mathrm{VO}_{2}$ in the unrelaxed (quenched) state, a thermally-relaxed state after being held at room temperature for 40 days after being relaxed above room temperature in a water bath, and a scan immediately after the cycle that was relaxed showing the resetting nature of this material. C) Powder XRD patterns measured at $-163 \mathrm{~K}$ for a $\mathrm{B}_{0.052} \mathrm{VO}_{2}$ sample in the relaxed and unrelaxed states of the $\mathrm{M} 1$ phase. The unrelaxed sample was heated to $100^{\circ} \mathrm{C}$ and then rapidly 
cooled to $-163 \mathrm{~K}$. Thermal-relaxation profilesand DSC scans before and after resetting are provided for the 7 (D, F) and 28 (E, G) days before low-temperature XRD.

Table S2. Calculated formation energies and lattice parameters Formation energies and atomic coordinates of all unique interstitial $B$ sites in the $\mathrm{M}_{1}$ and $\mathrm{R}$ unit cells as well as calculated $\mathrm{M}_{1}$ lattice parameters for different levels of interstitial B doping. Sites denoted with an (*) indicate the sites in a distorted and unrelaxed intermediate $\mathrm{M}_{1}$ phase calculated as metastable when transitioning from rutile in a doped 97 atom $2 \times 2 \times 2$ supercell.

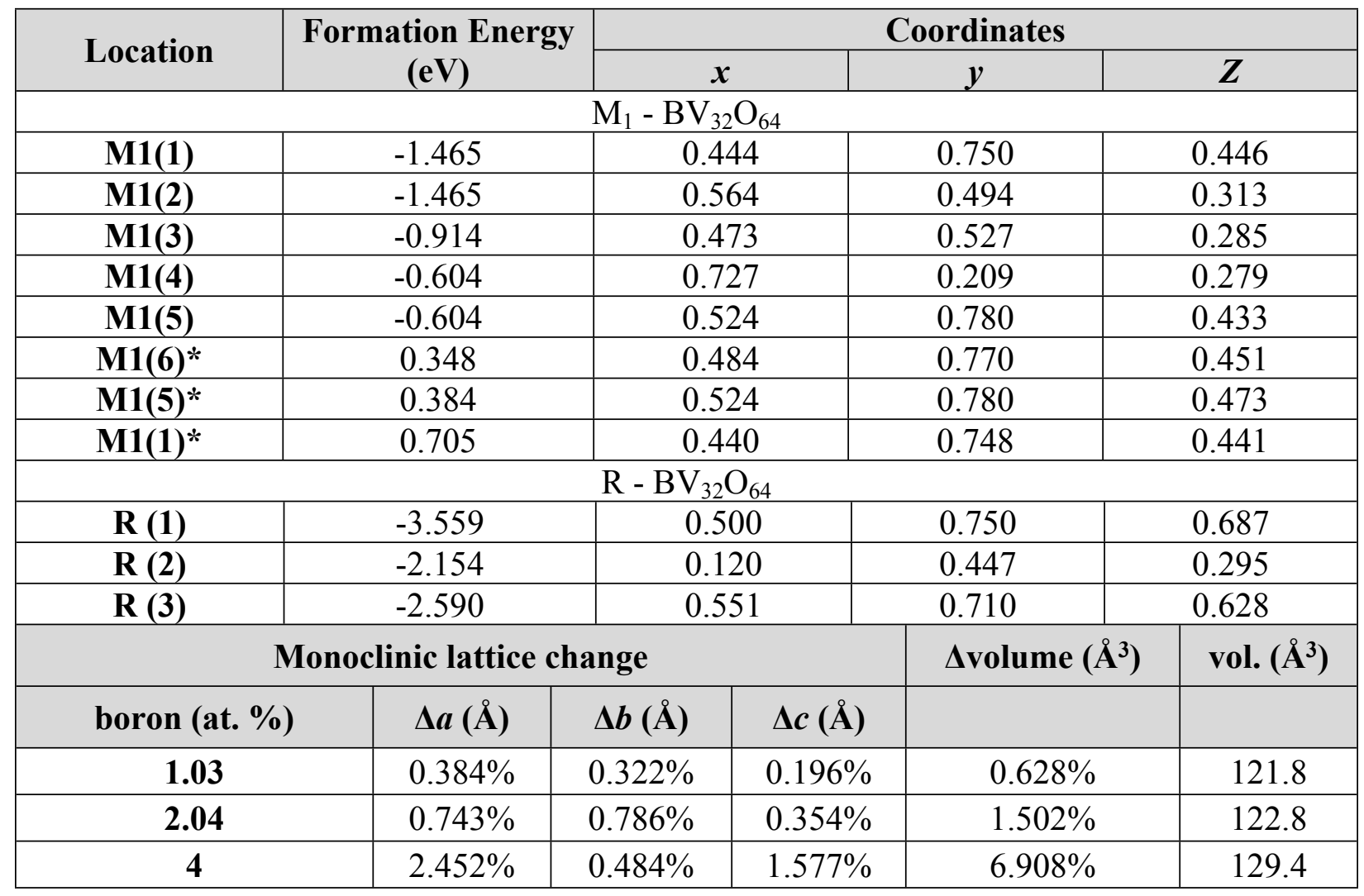



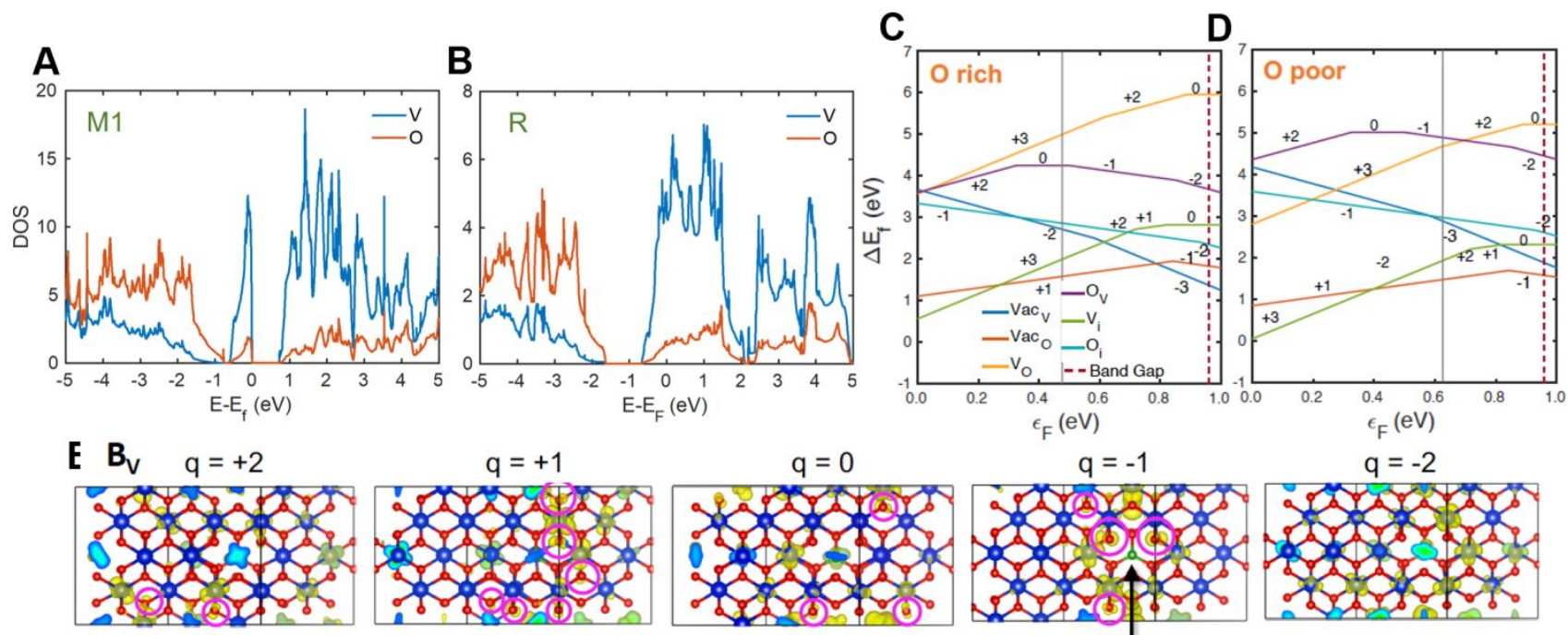

$q=-1$
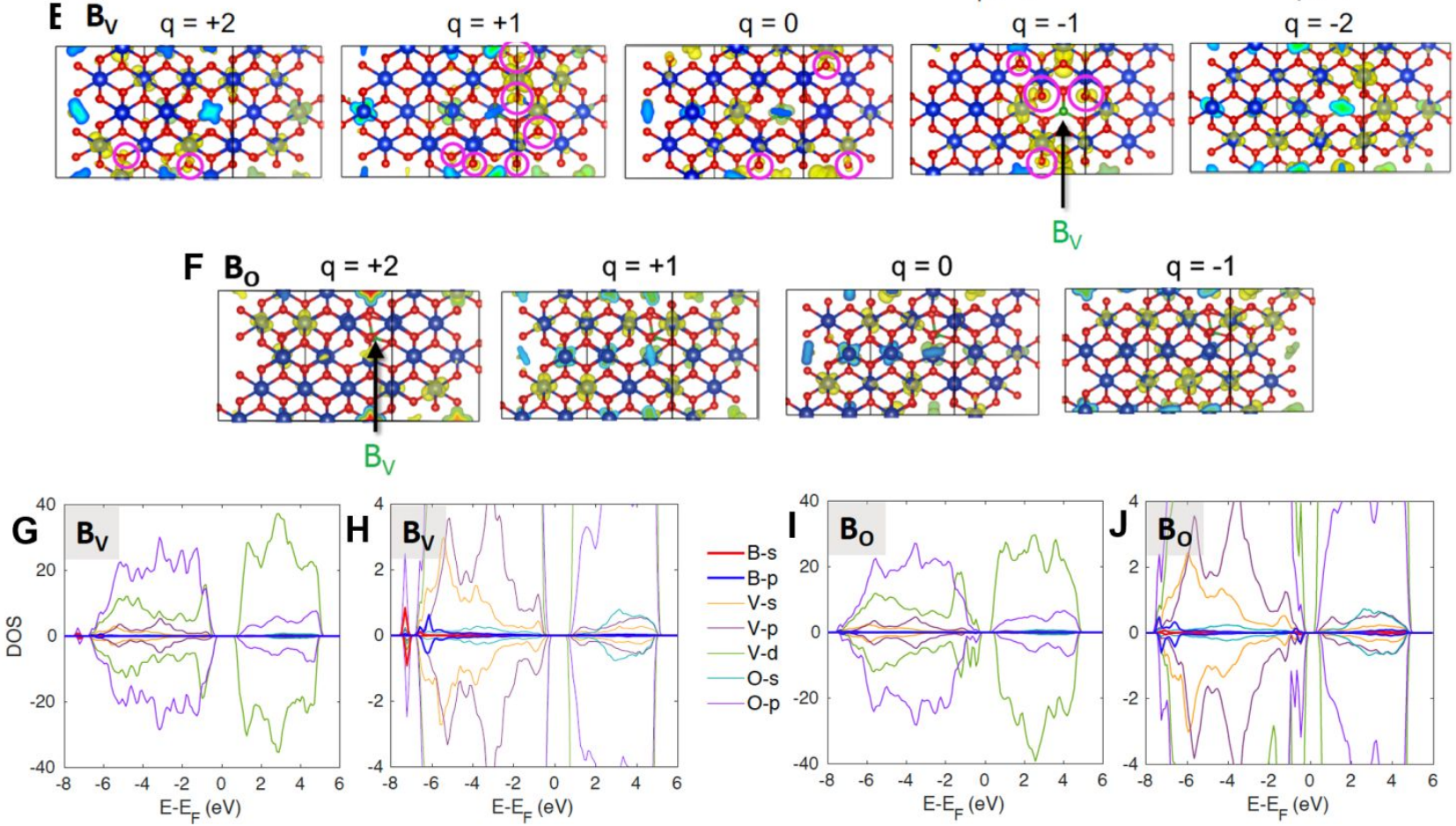

Fig. S7: Defect and band structure calculations. Density of states for (A) $M_{1}$ and (B) R phases respectively, using a $U$ value of $3.4 \mathrm{eV}$, which captures the insulating nature of the $\mathrm{M}_{1}$ polymorph and the metallic nature of the rutile polymorph. Native defect diagrams under (C) Orich and (D) O-poor conditions. The vertical grey line indicates where the equilibrium Fermi level is pinned by the native defects. Charge density of the highest energy valence states for (E) $\mathrm{B}_{\mathrm{V}}$ and $(\mathrm{F}) \mathrm{B}_{\mathrm{O}}$ defects with various charge states. In all cases, the charge is delocalized on $\mathrm{V}$ and $\mathrm{O}$ atoms instead of being localized around the $\mathrm{B}$ atom, which is expected from shallow defects. Purple circles indicate the electron density on oxygen atoms in the $\mathrm{B}_{\mathrm{V}}$ defect cell. Analogous to the discussion of the $\mathrm{B}_{\mathrm{v}}$ defect, the charges associated with $\mathrm{B}_{\mathrm{O}}$ defect are delocalized also indicated in the also the 0 charge state orbital-resolved DOS plots for $(G, H) B v$ and $(I, J) B_{O}$ defects. Hence, no significant lattice distortion is observed in proximity of the B atom. $\mathrm{H}$ and $\mathrm{J}$ are respective magnified views of $\mathrm{G}$ and I orbital-resolved projected DOS plots. The electronic states associated with the boron atom are mainly located within the deep valence band around -8 to $-6 \mathrm{eV}$ below the Fermi level, making it unlikely to induce significant electron density around the B atom near the Fermi level. This is consistent with Fig. S7C-D where the top valence electrons are mostly delocalized across the $\mathrm{V}$ and $\mathrm{O}$ atoms instead of the $\mathrm{B}$ defect. 

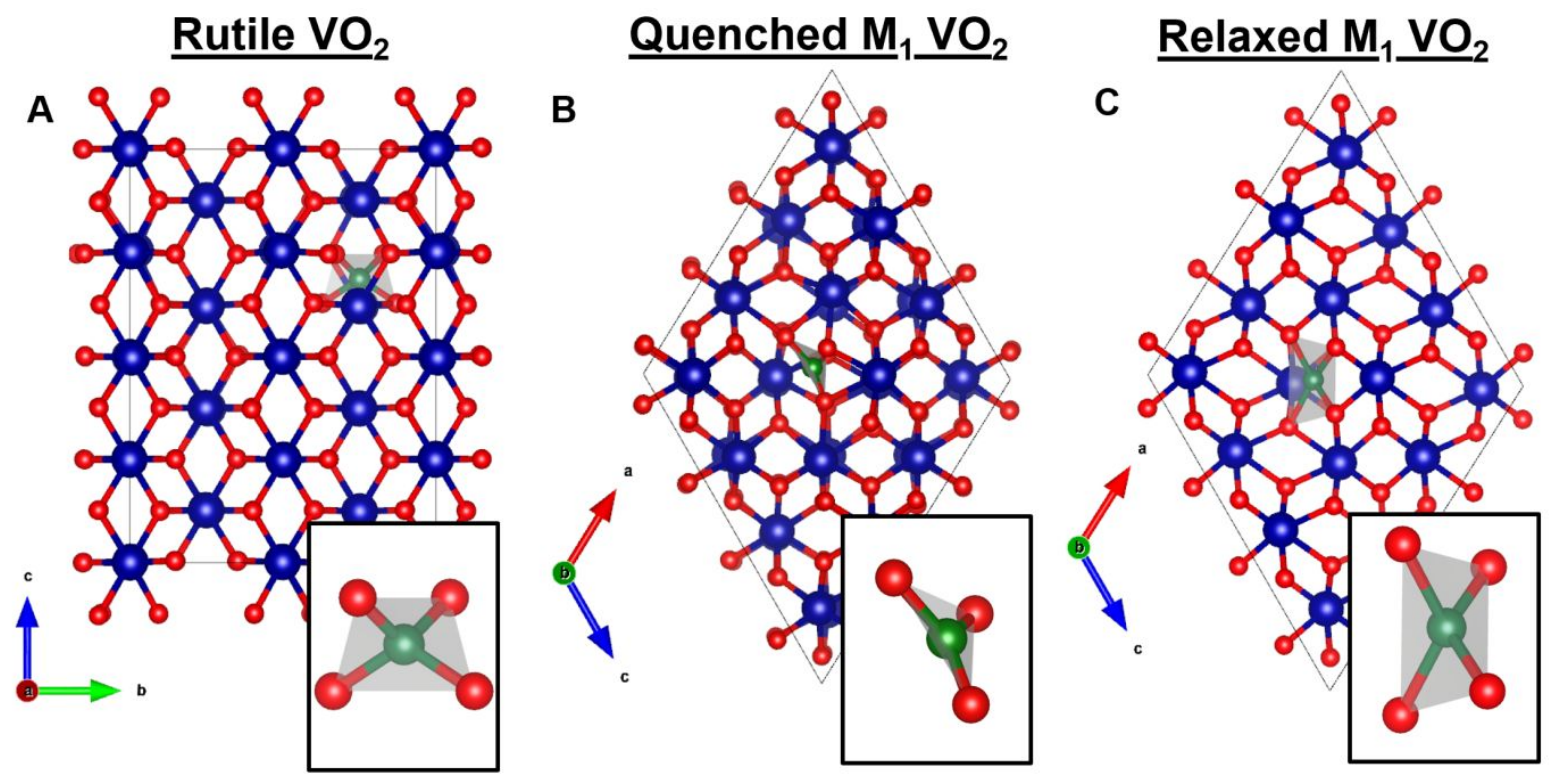

Fig. S8 Calculated suspercells: DFT calculated supercells for B-doped $\mathrm{VO}_{2}$, illustrating the most thermodynamically favorable interstitial sites for B incorporation for $\mathrm{R}(\mathrm{A}, \mathrm{R}(1))$, quenched $\mathrm{M}_{1}(\mathrm{~B}, \mathrm{M} 1(6))$, and relaxed $\mathrm{M}_{1}(\mathrm{C}, \mathrm{M} 1(1))$. Vanadium atoms are depicted as blue spheres, oxygen atoms as red spheres, and $\mathrm{B}$ atoms as green spheres. Lattice parameters for the doped $\mathrm{M}_{1}$ structure with different concentrations of boron can be found in Table S2. Insets show oxygen coordination of boron in each respective state.

Table S3. Boron spectral features reference Assignment of $\mathrm{B}-\mathrm{O}$ electronic transitions to spectral features in B K-edge XANES spectra using B standards.

\begin{tabular}{|l|l|l|l|l|}
\hline Assignment & $\begin{array}{l}\text { Incident } \\
\text { Photon } \\
\text { Energy }(\mathrm{eV})\end{array}$ & Standard & Structure & References \\
\hline $\begin{array}{l}\mathrm{B} 1 \mathrm{~s} \rightarrow \pi^{*} \mathrm{~B}-\mathrm{O} \\
\text { trigonal) }\end{array}$ & 194.4 & $\mathrm{H}_{3} \mathrm{BO}_{3}, \mathrm{~B}_{2} \mathrm{O}_{3}$ & \\
\hline $\begin{array}{l}\mathrm{B} 1 \mathrm{~s} \rightarrow \sigma^{*} \mathrm{~B}-\mathrm{O} \\
\text { trigonal) }\end{array}$ & 203.0 & $\mathrm{H}_{3} \mathrm{BO}_{3}, \mathrm{~B}_{2} \mathrm{O}_{3}$ & \\
\hline $\begin{array}{l}\mathrm{B} 1 \mathrm{~s} \rightarrow \sigma^{*} \mathrm{~B}-\mathrm{O} \\
(\text { tetrahedral) }\end{array}$ & 198.2 & cubic-BN & $22,38-41$ \\
\hline
\end{tabular}




\begin{tabular}{|l|l|l|l|l|}
\hline $\begin{array}{l}\mathrm{B} 1 \mathrm{~s} \rightarrow \sigma^{*} \mathrm{~B}-\mathrm{O} \\
\text { (tetrahedral) }\end{array}$ & cubic-BN, $\mathrm{BPO}_{4}$ \\
$\begin{array}{l}\text { multiple scattering } \\
\text { resonances }\end{array}$ & 200
\end{tabular}



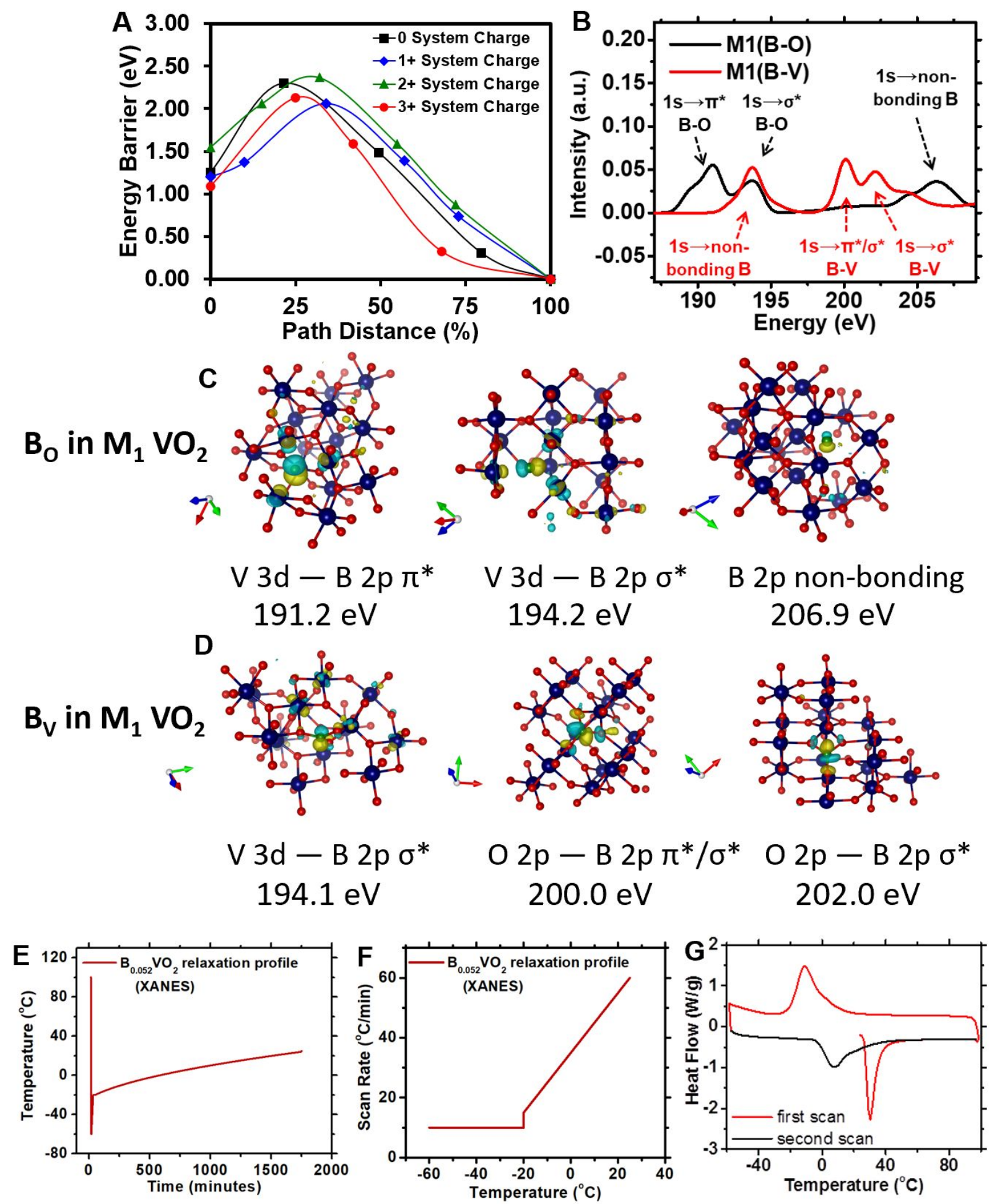

Fig. S9: Additional NEB and XANES details A) Minimum energy pathways obtained from NEB calculations when different charges were added to the supercell. B) Calculated B K-edge XANES spectra of substitutionally B-doped $\mathrm{VO}_{2}$ when $\mathrm{B}$ occupies an $\mathrm{O}$ site (black) or a $\mathrm{V}$ site (red). Final state assignments of the spectral features are assigned based on the symmetries of the states observed in the isosurface plots shown in (C) and (D). Features are labeled with their 
character as assigned from isosurface plots of the final states. Isosurfaces are furthermore labeled with the energy of the transition feature. The absorption features at $191 \mathrm{eV}$ and $194 \mathrm{eV}$ for a B atom in a $\mathrm{O}$ site are assigned to the excitation of a core $\mathrm{B} 1 \mathrm{~s}$ electron to $\pi^{*}$ and $\sigma^{*}$ states, respectively, associated with hybridization between V $3 \mathrm{~d}$ and B $2 \mathrm{p}$ states. The absorption feature at $206 \mathrm{eV}$ is assigned to a non-bonding B $2 \mathrm{p}$ state. The absorption feature at $194 \mathrm{eV}$ for a B atom in a V site is assigned to a non-bonding B $2 p$ state. The isosurface structure associated with the absorption feature at $200 \mathrm{eV}$ depicts both $\pi^{*}$ and $\sigma^{*}$ character for the excitation of a core B $1 \mathrm{~s}$ electron to a hybridized $\mathrm{O} 2 \mathrm{p}-\mathrm{B} 2 \mathrm{p}$ state. The final absorption feature at $202 \mathrm{eV}$ is assigned to the excitation of a core B 1 s electron to a O $2 p-B$ 2p hybrid $\sigma^{*}$ state. (E,F) Thermal DSC

profile expressed as (E) temperature $v s$. time and $(\mathrm{F})$ scan rate $v s$. temperature, used to thermallyrelax the $\mathrm{B}_{0.052} \mathrm{VO}_{2}$ sample to room temperature prior to Boron K-edge XANES spectroscopy measurements (shown in Figure 5B). G) DSC measurement of the thermally-relaxed $\mathrm{B}_{0.05} \mathrm{VO}_{2}$ sample taken immediately following Boron K-edge XANES analysis shown in Fig. 5B. 